\title{
O SIMBOLISMO DO JADE NOS TEOAMOXTLI DO GRUPO BORGIA
}

Leila Maria França*

FRANÇA, L.M. O simbolismo do jade nos teoamoxtli do Grupo Borgia. Rev. do Museu de Arqueologia e Etnologia, São Paulo, 14: 225-239, 2004.

RESUMO: Os antigos mesoamericanos atribuíam ao jade e similares um valor excepcional. A cor verde e sua semelhança com a água e a vegetação deram origem a uma complexa elaboração simbólica que superou os limites do âmbito aquático, tornando-o expressão máxima de preciosidade. Um olhar sobre os livros pictóricos rituais - teoamoxtli - e do glifo chalchihuitl (jade) dentro do sistema de escrita mesoamericano permite verificar algumas regras de emprego que evidenciam particularidades de seu valor aquático e de fertilidade.

UNITERMOS: Jade-Mesoamérica-Simbolismo aquático-Códices pré-hispânicos.

\section{Introdução}

O jade foi um dos materiais mais importantes na ordenação do universo cultural mesoamericano. ${ }^{1}$ Símbolo de poder e riqueza foi, antes de tudo, artigo escolhido para presentear os deuses e os grandes senhores, para consagrar edifícios, acompanhar os mortos na vida além túmulo, e curar diversas enfermidades. Isto porque, devido a qualidades especificas como a cor verde, brilho, dureza, durabilidade e raridade, este mineral incorporou, nesta área, um sem-número de significados relacionados a um complexo sistema

(*) Museu de Arqueologia e Etnologia da Universidade de São Paulo. Doutoranda em Arqueologia, bolsista da FAPESP. Centro de Estudos Mesoamericanos e Andinos CEMA-USP. lefranca@usp.br

(1) Jade, aqui, significa jade social, termo usado pelos especialistas, que incorpora, além da jadeíta, pedras verdes de menor valor, como serpentina, quartzos e outras que eram usadas na confecção de artigos de luxo e de culto entre as populações mesoamericanas. simbólico vinculado às águas e a fertilidade, conferindo-lhe o mais alto nível de preciosidade e transformando-o no item número um dos artigos desejóveis.

As crônicas do século XVI, bem como os textos de autoria indígena transcritos ao alfabeto, atestam a importância deste material para as populações pré-hispânicas, e estes últimos em especial, evidenciam o seu valor e importância segundo uma visão, diríamos, mais próxima de uma concepção indígena tradicional (França 1999).

Os testemunhos arqueológicos, por sua vez, são extremamente eloqüentes quanto ao emprego simbólico do jade, revelando sua presença, sobretudo em contextos funerários, votivos e cerimoniais desde o Horizonte Olmeca ou Período Formativo (1500-100 a.C.) até o Pós-Clássico Tardio (1200-1519), às vésperas da chegada dos europeus. Naturalmente, este uso se intensificou a partir do Período Clássico quando o Estado se desenvolveu plenamente e com ele, o acesso aos artigos de luxo - por meio do controle das regiões produtoras, do comércio e de um sistema redistributivo - que tinham como objetivo garantir a 
manutenção da hierarquia social, dos cultos religiosos e das trocas de presentes entre as elites.

Para os anos que antecedem a Conquista, portanto, sobretudo no México Central, a arqueologia revela um uso intensivo do jade e demais pedras verdes - chalchihuitl em nahuatl - especialmente em contextos oficiais, que apontam para o uso na esfera de prestígio e de suporte a uma religião estatal, essencialmente vinculados àquele complexo aquático e o culto a Tlaloc.

Neste artigo, propomos um olhar sobre um outro tipo de documento - genuinamente indígena - mas cuja leitura, sabemos, não constitui tarefa simples: os amoxtli, livros escritos a partir do sistema pictoglífico pré-hispânico, conhecidos como códices. Apesar disso, acreditamos que um exame cuidadoso dessas fontes poderá oferecer informações importantes sobre o papel do chalchihuitl na composição dos textos indígenas relativos ao simbolismo aquático, e conseqüentemente de seu significado, como forma, inclusive, de ampliar nosso conhecimento acumulado a partir do estudo das fontes alfabéticas e arqueológicas. Em outras palavras, pretendemos abordar, desde uma documentação produzida pelos próprios indigenas, como se dava a associação entre o chalchihuitl e o simbolismo aquático, bem como sua importância no MéxicoAntigo.

O material selecionado é composto pelo conjunto dos códices do Grupo Borgia pertencentes ao horizonte Mixteco-Puebla, todos presumidamente de origem pré-hispânica: Borgia, Vaticano B, Laud, Fejérváry-Mayer e Cospi. Presume-se que estes teoamoxtli ou livros rituais seriam um pouco anteriores à Conquista, pertencendo, portanto, ao Pós-clássico Tardio, período em que o jade assume, progressivamente, um papel cerimonial mais amplo.

\section{O significado aquático do chalchihuitl}

Sob o ponto de vista formal, o chalchihuitl pode ser representado, nos códices do Grupo Borgia, como conta ou colares de contas (ou discos, como preferem alguns) verde, vermelha, branca, às vezes com um núcleo amarelo; ou como um quincunce ou uma sucessão deles, podendo ser um retângulo com um círculo ao centro, de cores verde e ocre, ou ainda um grande círculo (geralmente vermelho, com núcleo amarelo) com quatro pequenas contas brancas em sua parte externa, distribuídas simetricamente (Fig. 1).

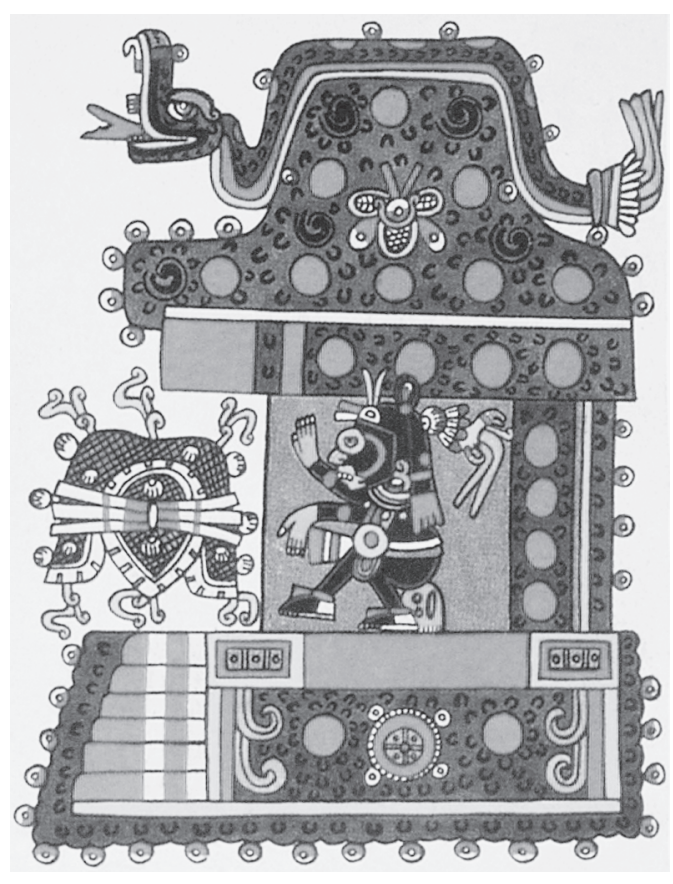

Fig. 1 - Algumas formas de representação do chalchihuitl na plataforma do templo: nos contornos, no centro e nas esquinas superiores (Borgia, 35).

Em seu magistral estudo Les Jades chez les Astèques, Marc Thouvenot (1982) expõe toda a complexidade do sistema de representações pictoglíficas do chalchihuitl nestes e em outros códices, sua infinita variedade formal e seus múltiplos sentidos. O chalchihuitl pode assumir a função de glifo toponímico, antroponímico, de ornamento, de tributo além de estar presente na composição de outros glifos, como por exemplo, Ollin (movimento) e Tonatiuh (sol). Em alguns dos casos, sobretudo nos nomes de lugares e pessoas, possui um valor fonético bem preciso.

Mas, devido ao seu alto valor dentro das culturas mesoamericanas, por trás de todos estes usos está a noção essencial que constitui a causa máxima de suas múltiplas funções: a idéia de preciosidade. Entre estas funções, a lingüística é uma das mais recorrentes: chalchihuitl é o glifo que designa o conceito de precioso dentro do sistema de escrita mixteco-nahua, e é a respeito dessa função conotativa que as questões relacionadas ao valor simbólico são evidenciadas e por isso mesmo, serão aqui, 
FRANÇA, L.M. O simbolismo do jade nos teoamoxtli do Grupo Borgia. Rev. do Museu de Arqueologia e Etnologia, São Paulo, 14:225-239, 2004.

objetos de análise. ${ }^{2}$ Algumas considerações sobre suas funções ornamentais poderão ser feitas, mas apenas quando possuir relevância dentro do tema estudado.

Mas, mesmo dentro desta categoria ampla de significados metafóricos e cerimoniais, encontraríamos inúmeras referências, pois, em geral, esses contextos vêm acompanhados do glifo precioso. Existe, no entanto, um contexto muito particular e recorrente no qual o chalchihuitl desempenha este papel e que, do nosso ponto de vista, constitui a razão mesma de sua eleição como matéria preciosa: o simbolismo aquático. ${ }^{3}$

O valor aquático do chalchihuitl pode ser evidenciado, portanto, já na sua forma de representação, e aqui as fontes materiais nos ajudam a compreender a razão de sua importância, devida ao paralelo da conta com as gotas de água. Esta relação é evidenciada pelos contextos arqueológicos que as apresentam, por exemplo, dentro de vasos Tlaloc e outras divindades da fertilidade ou, ainda, na composição de ambientes aquáticos como as representações do inframundo nas oferendas do Templo Mayor de Tenochtitlan, quando aparecem associados a conchas e outros objetos marinhos.

A evidência material demonstra, igualmente, $\mathrm{o}$ uso do chalchihuitl na demarcação do centro e das quatro direções, padrão que está de acordo com a própria representação glífica. Tal configuração revela a associação intrínseca entre o chalchihuitl e a superfície terrestre, marcada pelo movimento solar anual, com os quatro pontos intersolsticiais (Sprajc 2001) e um centro, dos quais o quincunce e o quadrante (nacxit xochitl = flor de quatro pétalas) são as duas maiores expressões (Brotherston 1997:119-140). Concebido como quincunce - que tem como referência uma paisagem de montanhas -, o chalchihuitl faz recordar o Tlalocan, a grande montanha administrada por Tlaloc e seus ajudantes, paraíso da fertilidade dividido em quatro rumos. Um outro elemento que

(2) A respeito da infinidade de formas de representação do glifo chalchihuitl, ver Thouvenot (1982).

(3) No sentido que lhe dá Mircea Eliade (1993: 336): um sistema que vincula a água, a terra, a lua e outros fenômenos naturais que representam o aspecto feminino do universo. Segundo este autor, simbolismo aquático é o mais totalizador dentro das experiências humanas com o sagrado. vem reforçar tanto o seu significado aquático quanto sua associação com Tlaloc é o seu uso privilegiado - sob forma de colares, pingentes, brincos e círculos ao redor dos olhos - na composição da imagem da divindade (Fig. 2).

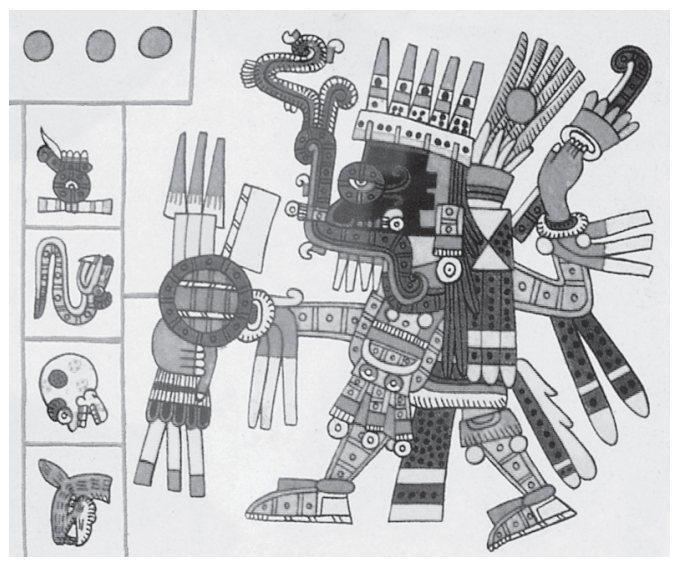

Fig. 2 - Tlaloc. Boca, círculo ao redor dos olhos, colar e escudo de chalchihuitl. Note-se que os membros e os pés da divindade são representados com chalchihuites amarelo/ocre (Borgia, 25).

A associação de Tlaloc com o mundo aquático é, como sabemos, um fenômeno antigo na Mesoamérica, embora, tenha sido conhecido por distintos nomes nas diferentes culturas e possuído, provavelmente, atributos específicos de matizes locais. As representações do Grupo Borgia estão pautadas em uma cosmovisão de raízes antigas dentro da Mesoamérica, que incluía um complexo culto relacionado aos fenômenos naturais - em particular, no âmbito aquático. 4 Tais crenças vinculadas ao âmbito do inframundo, teriam resultado no estabelecimento de uma geografia sagrada: as montanhas, as grutas e cavernas, as fontes, os rios, as árvores e a vegetação constituem zonas liminares de grande importância, e por isso

(4) Uma outra distinção se faz, aqui, necessária. Sabe-se que existem, sobretudo com respeito a Teotihuacan, duas manifestações distintas do chamado Tlaloc: um Tlalocjaguar relacionado à guerra e um Tlaloc-crocodilo relativo ao mundo aquático e às chuvas, cujos atributos principais são o raio em uma das mãos e um jarro d'água em outra, e é deste personagem que tratam os códices em questão. Ver Paztory (1974). 
mesmo, são temas recorrentes dentro do sistema de escrita mesoamericano (Heyden 1998a; 1998b). Para uma época mais tardia, sabemos, por intermédio de ampla documentação, que esta geografia sagrada compara a superfície da terra a uma grande montanha dentro da qual se armazenam as águas, o coração das sementes e de outros seres vivos, e que se ligam à superfície por meio das grutas, das fontes e dos rios. Tal montanha é concebida como o Tlalocan (lugar de Tlaloc), que, como dissemos, está dividida em quatro partes, em cada uma das quais um dos quatro tlaloques (pequenos auxiliares do deus) derrama a chuva com seus vasos de chalchihuitl (Historia de los mexicanos por sus pinturas; Broda 1982; 1996).

Mas, a distribuição espacial na Mesoamérica não pode ser compreendida sem a dimensão temporal. Por tratar-se de uma divindade vinculada aos fenômenos naturais existe uma ligação muito estreita entre esta e o ciclo solar de $360+5$ dias. Os quatro rumos do universo - as direções intercardinais: noroeste, nordeste, sudeste e sudoeste - relacionam-se, assim, com os movimentos do sol que cruzam o céu, daí que o quincunce parece ter uma conotação ao mesmo tempo, espacial e temporal. Além disso, no cômputo calendárico, as quatro direções estão relacionadas às trezenas do xiuhmolpilli, ciclo de 52 anos $(4 \mathrm{x}$ $13=52$ ), e aos quatro signos que encabeçam os anos solares: acatl, tecpatl, calli e tochtli (junco, pedernal, casa e coelho - respectivamente).

Finalmente, as quatro direções estão associadas às trezenas dos dias do tonalpohualli, ciclo ritual de 260 dias baseado na gestação humana.

Apresentamos, a seguir, uma breve análise das imagens relacionadas ao simbolismo aquático que tem como figura central Tlaloc, tradicionalmente reconhecido como entidade responsável pela chuva e fertilidade da terra e, eventualmente, a sua contraparte feminina-Chalchiuhitlicueprotetora das águas terrestres (rios, fontes e lagos). A descrição das imagens e de seu significado geral será breve e baseada na interpretação dos estudiosos; descreveremos apenas o suficiente para a compreensão do fenômeno que se quer tratar, ou seja, a representação do chalchihuitl. Naturalmente, o que propomos é uma hipótese de leitura baseada em algumas imagens, mas cujos resultados poderão produzir algumas reflexões importantes.

\section{Borgia}

A análise das imagens do Códice Borgia é a mais trabalhosa devido à sua complexidade. As páginas escolhidas são 27 e 28 que representam Tlaloc relacionado ao centro e às quatro direções e seus correspondentes no cômputo calendárico cuja leitura segue em sentido anti-horário, iniciando-se no canto inferior direito de cada página.

Na página 27 (Fig. 3), Tlaloc vem representando as trezenas do xiuhmolpilli (ciclo de 52 anos sazonais), assumindo atributos de outras divindades. Cada trezena, que, na verdade, apresenta datas mais específicas, com dia e ano, prevê um destino para as colheitas. Sua leitura se inicia com Tlaloc, no oriente, assumindo na primeira trezena (ano IJunco, 2Crocodilo) aspecto de Lagarto. Assenta-se sobre um lagarto (a terra) que é fértil e o céu está nublado.

Para o dia 1Pedernal, do ano 1Morte, Tlaloc, amarelo, representa, ao norte, a segunda trezena com o aspecto de Morte. O céu está aberto, com raios de sol e a terra está seca: aqui a divindade assenta-se sobre uma terra árida, cheia de pedras e os gafanhotos devoram as espigas de milho.

No ano ICasa, dia $1 M a c a c o$, no terceiro período de 13 anos, Tlaloc está no rumo oeste, com aspecto de Macaco. O céu está coberto de nuvens e a terra em que se assenta está inundada: sinal de boa colheita.

Na última trezena, do dia 1 Coelho do ano 1Zopilote, a divindade na cor vermelha está ao sul, com aspecto de Zopilote. ${ }^{5}$ O céu está limpo, com muito sol, a terra está seca e os ratos devoram as espigas de milho, como sinal da má colheita.

No centro do mundo, vemos Tlaloc como vítima de sacrifício, sobre uma terra preciosa representada como um recipiente de chalchihuitl, dentro do qual o esperam duas jovens deusas das sementes. O céu está escuro, e contém nuvens e navalhas de pedernal que representam execução e sacrifício e o Sol se eclipsa.

Considerando os quatro rumos, temos dois períodos de seca, praga e más colheitas - ao norte e sul-e dois de colheitas favoráveis, em que há chuvas.

(5) Zopilote é uma ave de rapina, semelhante ao urubu, exclusiva da Mesoamérica e América Central, não tendo, portanto, equivalências em português. Por isso mantemos o termo em espanhol. 
FRANÇA, L.M. O simbolismo do jade nos teoamoxtli do Grupo Borgia. Rev. do Museu de Arqueologia e Etnologia, São Paulo, 14:225-239, 2004.

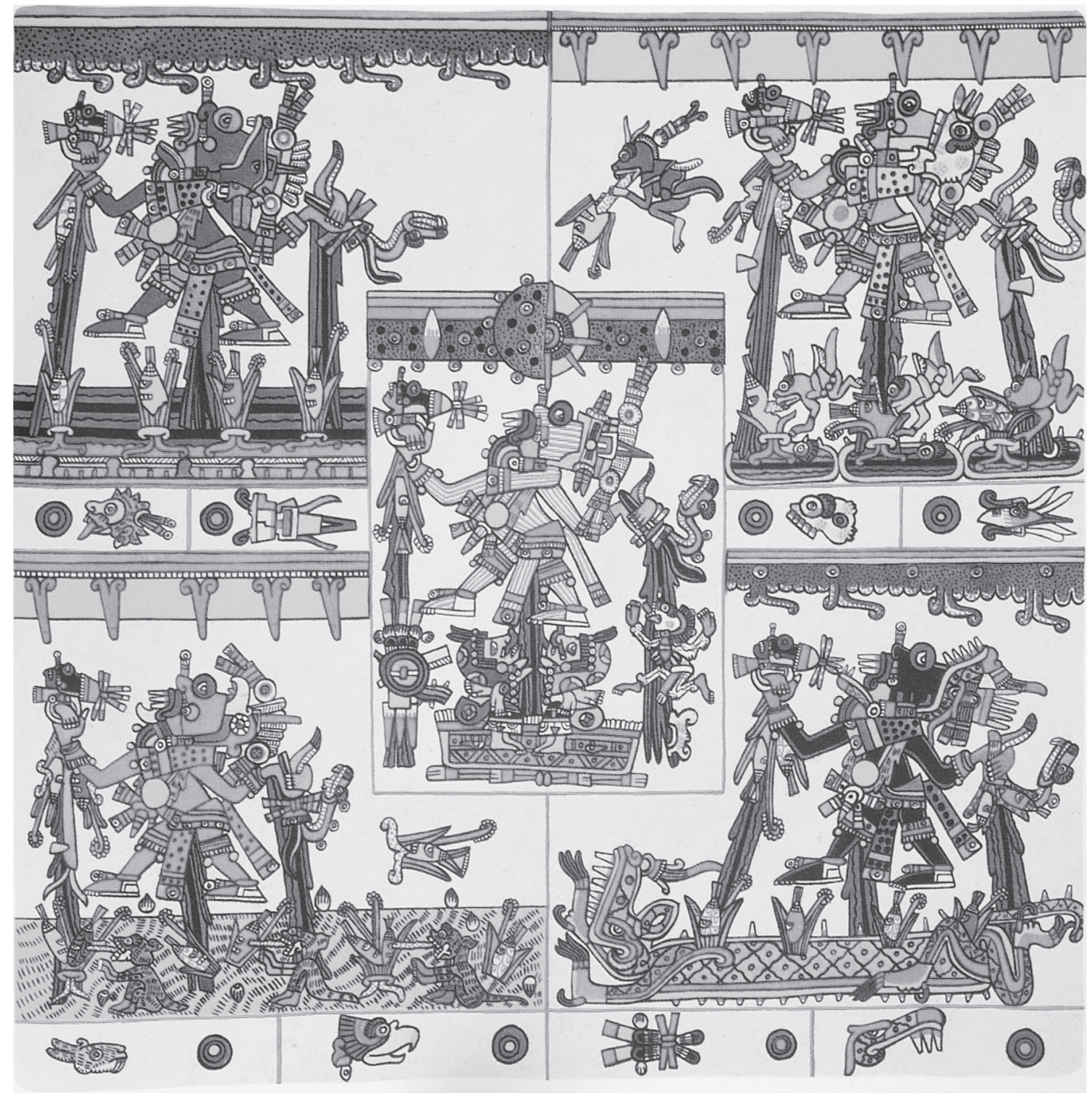

Fig. 3 - As trezenas do xiuhmolpilli (ciclo de 52 anos) e os prognósticos para a agricultura, representados por Tlaloc em suas cinco manifestações (Borgia, 27).

Na primeira trezena, o céu é nublado e escuro (a obscuridade está representada pelo 'olho estelar' um círculo metade branco, metade vermelho), expressando um céu carregado, e a terra assume seu aspecto fértil (lagarto), resultando em uma boa colheita. No canto oposto, o céu está nublado, mas não carregado, e a terra é representada por um lago - o que indica que já houve chuvas suficientes.

No centro temos um céu carregado e escuro, com navalhas de pedernal, provavelmente relacionadas ao aspecto de sacrifício da figura de Tlaloc.
Aqui, no centro do universo, ponto de tensão e equilíbrio, a terra é representada como um recipiente precioso (de chalchihuitl), cuja fertilidade é obtida por meio do sacrifício e de chuvas alvissareiras. Assim, os prognósticos de chuvas - revelados pelo aspecto do céu carregado - constituem a condição para a fertilidade da terra, a qual, precisamente no centro, é concebida como um chalchihuitl.

Na página 28 (Fig. 4), diferentemente da anterior, temos a seqüência dos cinco primeiros 


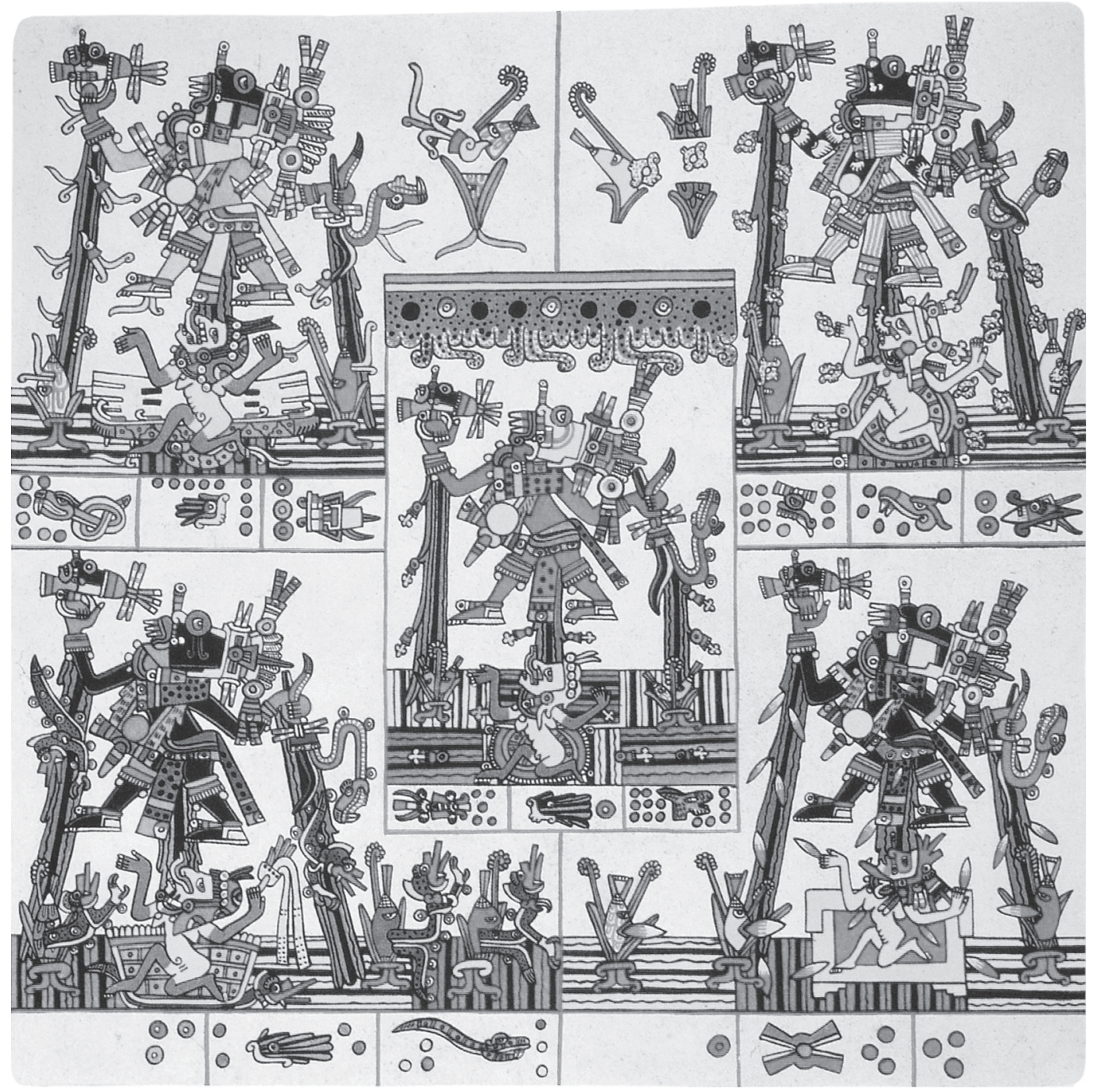

Fig. 4 - Prognóstico para a agricultura nos cinco primeiros anos do xiuhmolpilli, representado por Tlaloc em seus diferentes aspectos (Bórgia, 28).

anos do xiuhmolpilli, com a indicação de dias, e seus respectivos prognósticos para as colheitas. Em cada ano (ou direção) Tlaloc assume atributos de outros deuses. A leitura desta página inicia-se no canto inferior direito.

Para o ano 1Junco, (os dias aqui estão apagados) Tlaloc está no Oriente e manifesta-se como Tezcatlipoca. A terra é um caixa de tesouros (petlacalli) e a sua fertilidade está representada pela mãe de Quetzalcóatl (que, segundo o mito, o concebeu ao tragar um chalchihuitl). A chuva contém navalhas de pedernal que cortam as espigas de milho e a fertilidade.

O segundo ano, 2Pedernal com os dias 5 Crocodilo e 10Chuva, Tlaloc encontra-se com o aspecto de Tlahuizcalpantecuhtli (Senhor de Vênus) ao norte. Assenta-se sobre a terra representada como um grande pote de jade. A chuva contém granizo que atinge as espigas e a fertilidade da terra, representada por Xochiquetzal.

Os dias 9Água e 7Serpente do ano 3Casa apresentam Tlaloc no rumo oeste, manifestando-se 
como Xiuhtecuhtli. A terra é representada como a boca de um lagarto aberta, e a chuva contém chamas de fogo que queimam as espigas e a fertilidade representada pela deusa Xantico.

O quarto ano, 4Coelho, com os días 4Água e 6Serpente representa Tlaloc no Sul como Quetzalcóatl. A terra sobre a qual se assenta, é um recipiente de chalchihuitl e a chuva contém serpentes de vento que, segundo os intérpretes, destroem a espiga e a fertilidade que é Chalchiuhtlicue.

No centro do mundo está Tlaloc no ano 5Junco com os dias lÁgua e 13Veado. Manifestase entre um céu nublado e escuro e a terra, representada como um grande jade ou chalchihuitl em meio à milpa. A chuva contém flores, que caem sobre as espigas e sobre a deusa do milho que incorpora a fertilidade, num aspecto benéfico.

Mais uma vez, a representação do chalchihuitl é muito expressiva. Diferentemente da página 27, os quatro rumos não apresentam céu, e a terra é sempre representada como algo precioso. Entretanto, parece haver uma correlação entre as formas de representar a terra e os elementos que caem em forma de chuva. Tanto no Oriente como no Ocidente, sob as influências de Tezcatlipoca e Xiuhtecuhtli, respectivamente, a terra é representada por elementos preciosos não aquáticos e os fenômenos que caem do céu são símbolos quentes: no oriente, a terra é uma petlacalli (caixa de tesouros) e a chuva de facas sacrificiais; no ocidente, a terra é a face de um lagarto e a chuva é de fogo. Em contrapartida, nos quadrantes norte e sul temos a representação da terra como um vaso de chalchihuit e chuva de granizo ao norte, e ao sul, a terra como uma vasilha de jade e chuva de vento úmido. Ao contrário dos quadrantes leste e oeste, estes apresentam chuvas de elementos aquáticos e neles, não por acaso, a terra é representada como recipientes de jade, expressão de fertilidade e riqueza.

Mas é no centro, novamente, que a tensão se resolve e que aparece um elemento novo que é o céu. Tlaloc encontra-se sob um céu escuro, repleto de nuvens e tem aos seus pés a terra, que é um grande jade. Fica estabelecida uma vez mais a relação de complementaridade aquática entre céu e terra: nuvens que contêm chuva e a terra fértil, ao centro, que recebe a umidade, concebida como um chalchihuitl. Além disso, a chuva de flores (conhecido símbolo de fertilidade na Mesoamérica) reforça a idéia de fertilidade, coroando o equilíbrio da cena.

\section{Vaticano B}

Neste documento, selecionamos o capítulo correspondente à página 69 , intitulado pelos editores 'As cinco manifestações do deus da chuva'. Seu conteúdo é semelhante à página $27 \mathrm{do}$ Borgia, constituindo um conjunto de prognósticos para a atividade agrícola relacionados às quatro trezenas do ciclo de 52 anos, que correspondem aos quatro pontos cardeais, além do centro (Fig.5).

Para o dia 1Lagarto do ano 1 Junco da primeira trezena, Tlaloc apresenta-se em seu aspecto negro e está no Oriente, sob o signo Lagarto (caráter primordial e criativo). O céu está nublado e a terra, representada como um lagarto, é fértil. Nas mãos da divindade, uma planta de milho e um colar de jade expressam a idéia de boa colheita.

A segunda trezena, a do ano 1Pedernal, dia IMorte, vem representada por um Tlaloc amarelo situado ao norte e personificando o signo Morte. O céu está ensolarado e a terra é um monstro negro, duro e cheio de pedras. Nas mãos do deus, o milho está sendo devorado pelos insetos, o que significa fracasso na colheita.

Para o dia IMacaco do ano ICasa da terceira trezena, Tlaloc está no Ocidente, é azul e personifica o signo Macaco (caráter leviano e artístico). O céu está nublado e a terra cheia de água e Tlaloc segura a planta do milho com o colar de jade, significando que a colheita será abundante e rica.

Na quarta trezena, a do ano 1 Coelho, dia 1Zopilote, Tlaloc está no rumo sul, é vermelho e representa o signo Zopilote (ancião). O céu está ensolarado e a terra seca. A planta em sua mão está sendo comida pelos ratos, sinal de perda da colheita.

No centro, assentado sobre a face do Lagarto que é a terra, Tlaloc está pintado de listras vermelhas e brancas como vítima de sacrifício. Segura seu machado (metáfora de raio) em uma das mãos e na outra a planta do milho e o colar de jade. Abaixo, a representação de armas e ossos é interpretada como alusões à guerra e a morte, relacionadas, provavelmente ao sacrifício.

No códice Vaticano B, ao contrário do Borgia, o chalchihuitl é pouco usado. Aqui, ele está ausente do céu e da terra, aparecendo somente sob forma de colar, mas de maneira muito significativa: é empregado para indicar a prosperidade e abundância da colheita - a riqueza por excelência. 


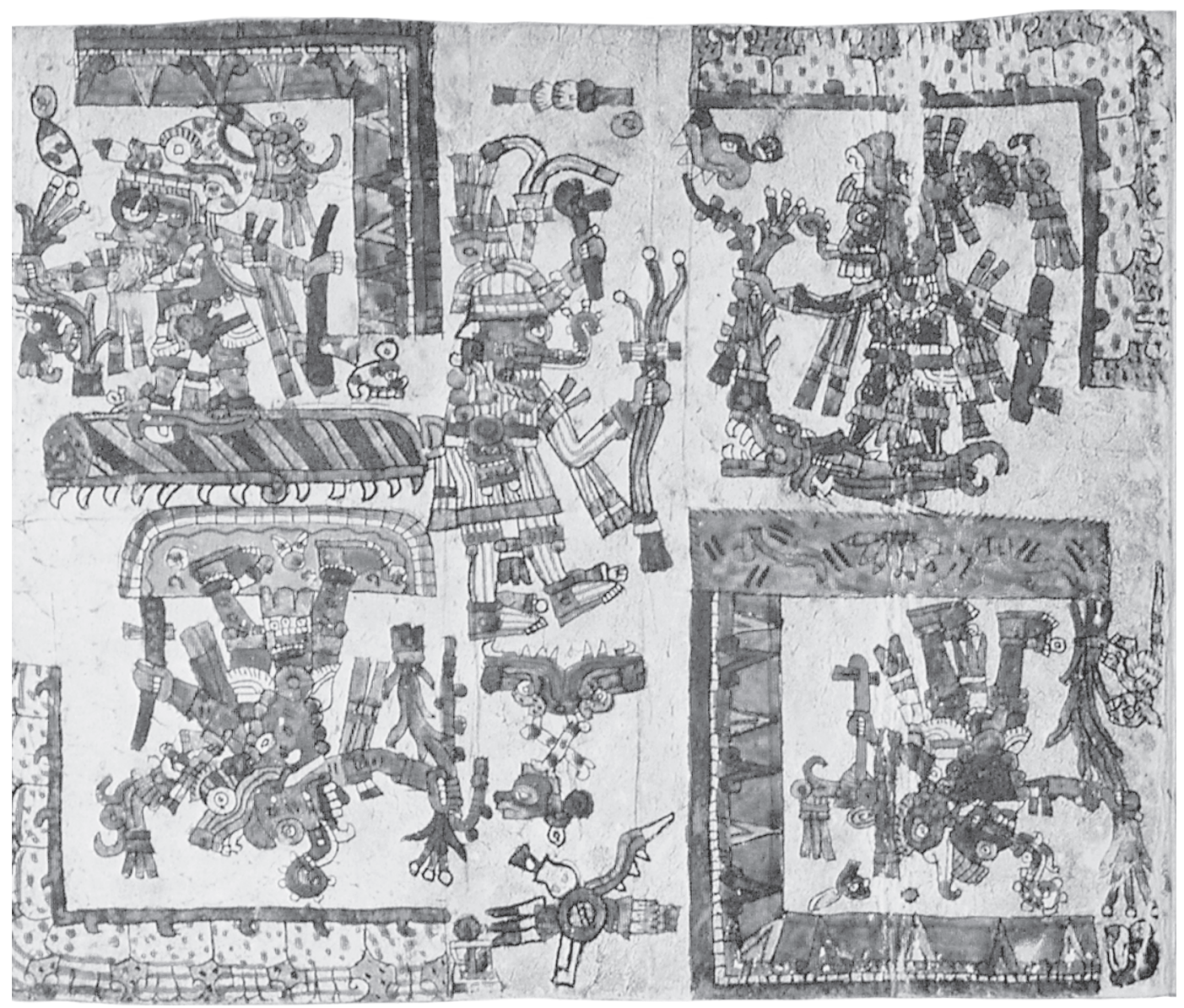

Fig. 5 - Tlaloc, em suas cinco manifestações, representando os prognósticos para a agricultura nas trezenas do xiuhmolpilli (Vaticano B, 69).

A relação dos colares com os âmbitos terrestres e celestiais pode ser explicada da seguinte maneira: Tlaloc está adornado com os colares de chalchihuitl somente nas trezenas onde há céu com chuva abundante (e não ensolarados) que propicia sua fertilidade natural (lagarto) ou água em abundância (lago).

Um dado significativo é que os adornos da divindade parecem ter uma correspondência qualitativa com a cena: nas trezenas favoráveis eles são muito visíveis, sobretudo na direção oeste em que a terra é cheia de água e seu colar é o mais elaborado. Na trezena do norte, nefasto, ele está ausente, embora seja visível (mas não muito elaborado) na trezena do sul, também nefasta. $\mathrm{O}$ fato é que nos três períodos favoráveis as jóias são visivelmente mais luxuosas.

\section{Laud}

Neste documento escolhemos a página 23 (Fig. 6) que tem como elemento central a figura de Tlaloc como senhor dos vinte signos calendáricos, segurando em uma das mãos seu chicahuaztli (cetro que representa a fertilidade) e na outra, seu bastão em forma de serpente de fogo (raio).

Na parte inferior da página, abaixo de Tlaloc, está o mar, onde nadam criaturas marinhas e o lagarto precioso que é a terra, ao centro, representado com um grande chalchihuitl em seu interior. No canto inferior esquerdo, acima do mar, está uma rã, que sob ordens da divindade, joga água no mar com um vaso de chalchihuitl. 


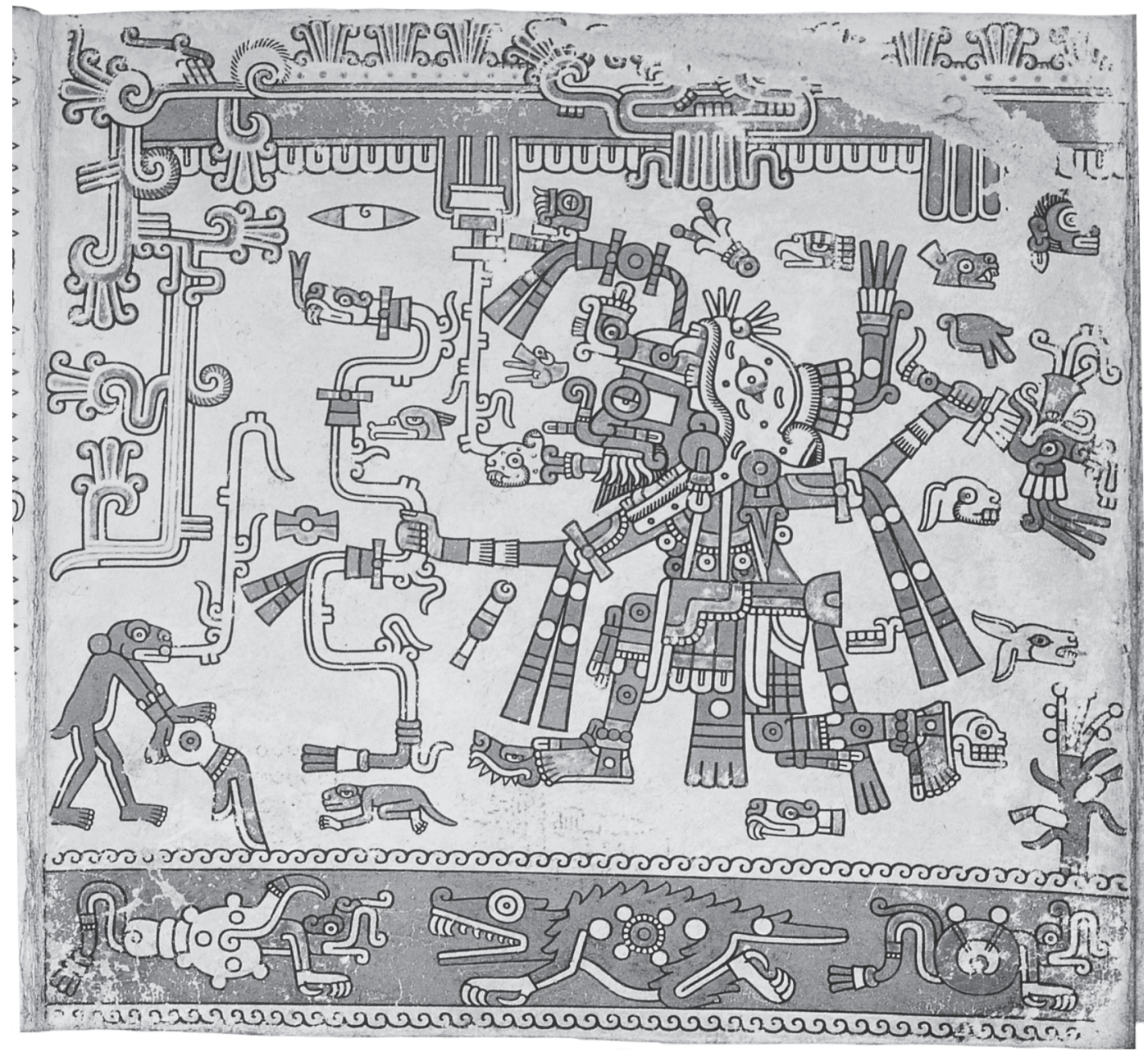

Fig. 6 - Tlaloc como senhor dos vinte signos do tonalpohualli (Laud, 23).

Nos chama a atenção, nesta imagem o vaso de chalchihuitl-como o dos tlaloques, com os quais estes derramam as águas sobre a terra - mas aqui, enchendo os oceanos. Além disso, o lagarto submerso (símbolo da terra) está ornado com um grande chalchihuitl em forma de quincunce, uma provável referência à fertilização da terra pelas águas do mar-fonte máxima de fertilidade (Broda 1982). Estes elementos confirmam, mais uma vez, a presença do chalchihuitl como expressão de fonte de água, de vida e fertilidade.

\section{Fejérváry-Mayer}

Na página 4 (Fig. 7) deste documento há uma referência importante a Tlaloc como um dos Nove
Senhores da Noite. De forma semelhante à representação descrita do Códice Laud, vemos Tlaloc sobre um grande lagarto (a terra) rodeado pelo mar, cuja língua se transforma na serpente de fogo, atributo do deus.

A oferenda à divindade, situada abaixo, está composta de milho, corações e instrumentos de sacrifício. Mais abaixo, ainda, as oferendas de ocote e hule são postas sobre o manancial de águas preciosas, lugar de culto à divindade, como também atestam as fontes escritas

O chalchihuitl aqui aparece no olho do lagarto - a terra - e no manancial das águas, mais uma vez, os dois elementos de máxima preciosidade na simbologia aquática. 


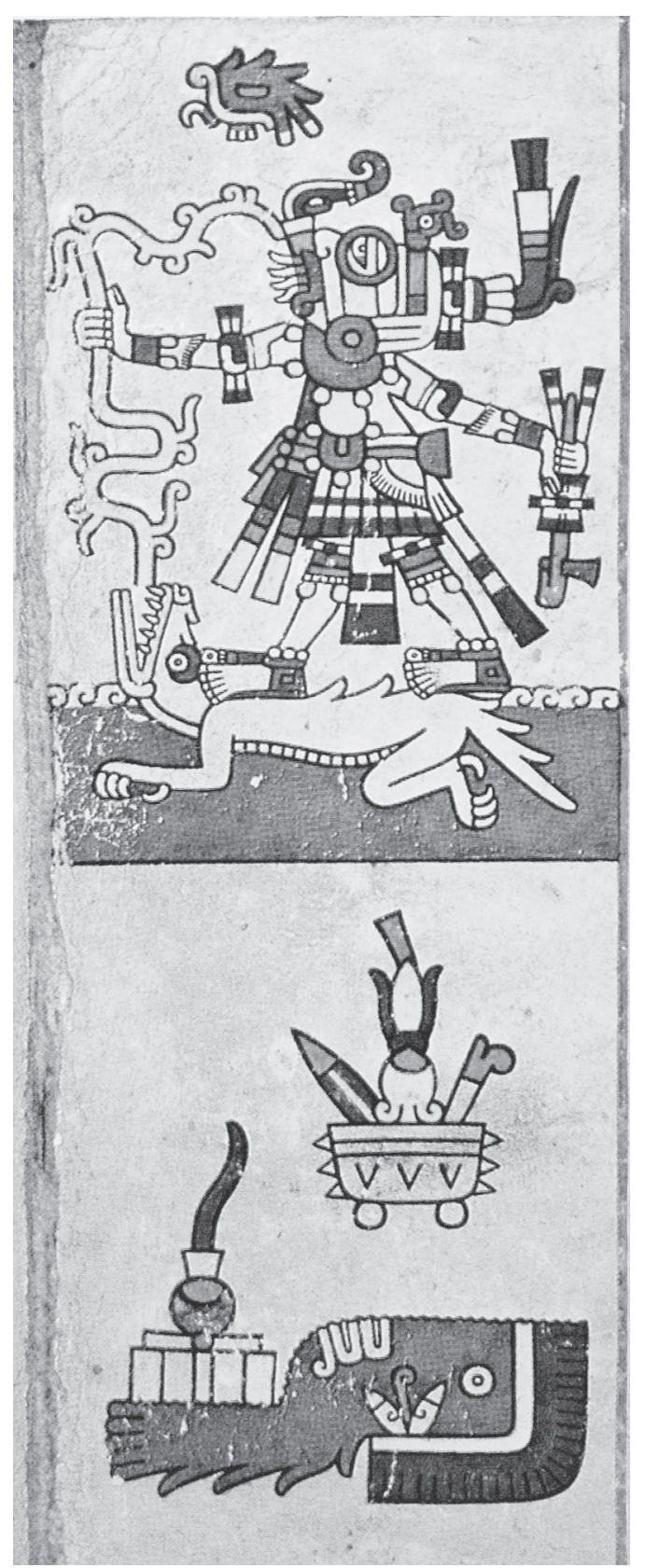

Fig. 7 - Tlaloc como um dos nove senhores da noite (Fejèrváry-Mayer, 4).

\section{Cospi}

Neste documento, a referência mais explícita a uma divindade aquática está relacionada não a Tlaloc, mas a Chalchiuhtlicue. Em um capitulo dedicado à incidência de Vênus sobre a sociedade, ${ }^{6}$ vemos na página 9 uma representação da segunda trezena do tonalpouhualli e do ciclo de Vênus de 584 dias sob a influência

Tlauizcalpantecuhtli, personificação do planeta. Nela, o Senhor Vênus perfura o coração de Chalchiuhtlicue, a deusa das águas, atingindo a árvore de jade (riquezas e a descendência) - o que representa um tempo de seca e miséria (Fig. 8).

Note-se, aqui, a árvore de jade em forma de quincunce que nasce da cabeça da deusa, referindo-se claramente aos quatro rumos do universo. Além disso, seu tronco é composto de chalchihuites e, da mesma forma, seus frutos, que nascem em cada uma das direções - apesar de que um deles não é visível, outro apenas parcialmente, como se estivessem fora da página - e que se constituem, por sua vez, de quincunces. O ataque de Vênus tem precisamente aqui, o sentido de atingir este domínio, que é interpretado como sustento, riqueza e descendência - naturalmente, de origem aquática.

\section{Conclusão}

O conjunto das imagens analisadas demonstra claramente a associação do chalchihuitl com as representações aquáticas e de fertilidade. Mais que isso, permite compreender sua importância na expressão, ao mesmo tempo, das águas, das chuvas, umidade e fertilidade, extraindo desses fenômenos, tão importantes para a manutenção da vida entre os antigos mesoamericanos, o seu sentido de precioso.

Podemos observar, inclusive, que a representação do chalchihuitl está construída dentro dos moldes espaciais da cosmovisão mesoamericana, tão detalhados pelas fontes indígenas de origem pictórica ou alfabética, conferindo-lhe um papel central.

O chalchihuitl é a expressão máxima da fertilidade da terra - na forma de um grande jade, um recipiente de jade ou sob a forma de um lagarto com jade - ou mesmo das águas terrestres ou oceânicas, constituindo, portanto, um símbolo, por excelência, do mundo subterrâneo, ao qual está ligada a superfície terrestre. Tal idéia pode ser

(6) Dentro da Cosmovisão Mesoamericana, o planeta Vênus é um símbolo ambivalente: benéfico em seu aspecto matutino e maléfico em seu aspecto vesperal. Este último, segundo se acreditava, trazia males e enfermidades. 


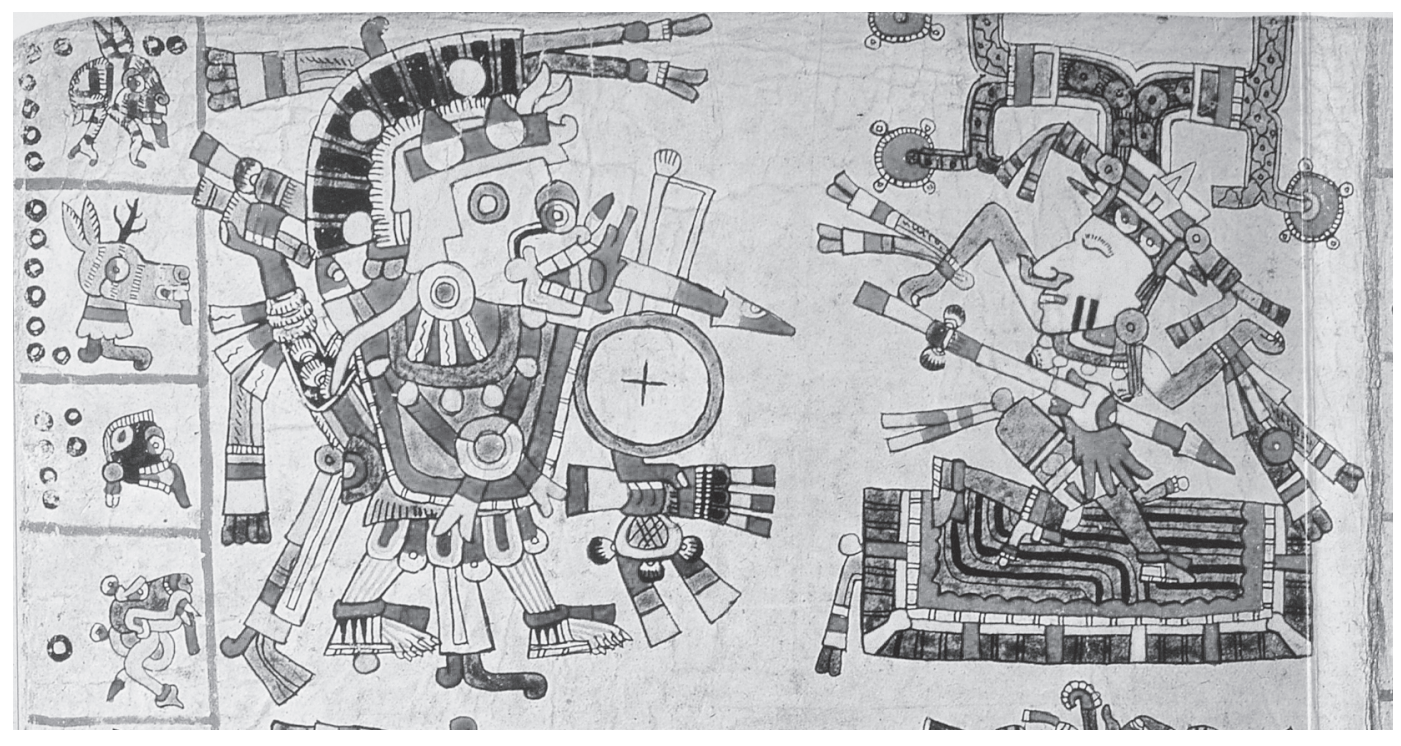

Fig. 8 - Na segunda trezena de Vênus, Chalchihuitlicue tem seu coração perfurado por Tlauizcalpantecuhtli (Cospi 9).

apoiada pela deposição do jade e similares nas camadas intermediárias e profundas dos depósitos espacialmente relacionados ao altar de Tlaloc, no Templo Mayor. ${ }^{7}$

Por outro lado, constitui um elemento importante na configuração deste nível intermediário do Cosmos, dividido em quatro rumos e um centro. Este papel de localizador do jade relativamente ao centro e às quatro direções cósmicas - que se manifesta freqüentemente através de sua relação com os tlaloques e o Tlalocan - está de acordo com os testemunhos das fontes escritas e materiais. Segundo os informantes de Sahagún, os chalchihuites provinham da terra dos Olmecas, uma terra fertilisima, por lo cual la llamaron los antiguos Tlalocán, que quiere decir, tierra de riquezas y paraiso terrenal (Sahagún, livro X, cap.XXIX, p. 97). A mesma fonte relata um ritual praticado nas festas de Etzalqualiztli, no qual se estendia uma esteira de junco e folhas junto ao adoratório de Tlaloc e sobre ela quatro chalchihuites redondos à

(7) Este fenômeno é o resultado dos dados gerados pela tese de doutorado da pesquisadora, intitulada $O$ Monte das Águas-queimadas: o Simbolismo das Pedras Verdes nas Oferendas do Templo Mayor de Tenochtitlan, México, que, por ocasião da entrega deste artigo, encontra-se em fase de conclusão. maneira de bolinhas; então o sacerdote do deus tomava um graveto pintado de azul com o qual tocava cada uma das bolinhas fazendo-as girar (idem, livro II, cap. XXV, p. 31-32).

Esta relação é, ainda, magistralmente ilustrada pela petlacalli de Tizapán (Fig. 9), em que vemos os quatro tlaloques vermelho, negro, branco e amarelo, nas quatro direções, com seus chalchihuites ao redor dos olhos, segurando o céu, representado por um enorme chalchihuitl. Além disso, nas oferendas do Templo Mayor, as contas de jade foram freqüentemente utilizadas para simbolizar o cosmos. Para citar dois exemplos, temos a oferenda 16/16-A, que apresenta no centro uma imagem de Xiuhtecuhtli - divindade que representa o centro do cosmos - com uma grande conta de jade e quatro outras menores demarcando os 4 pontos intercardinais (Fig. 10). A oferenda 41, um depósito em cista, traz em seu centro uma petlacalli cheia de estatuetas de pedra verde (substituta do jade) que representam os tlaloques, além de figuras zoomorfas relacionadas ao inframundo (peixes, rãs, serpentes, cães e aves aquáticas). Ao redor da petlacalli, interpretada como o próprio Tlalocan, os sacerdotes mexicas depositaram cinco fragmentos de pedra verde nas esquinas nordeste, noroeste e sudeste, e é possível que originalmente estivessem distribuídos de forma a demarcar os cinco rumos (Fig. 11). 
FRANÇA, L.M. O simbolismo do jade nos teoamoxtli do Grupo Borgia. Rev. do Museu de Arqueologia e Etnologia, São Paulo, 14: 225-239, 2004.

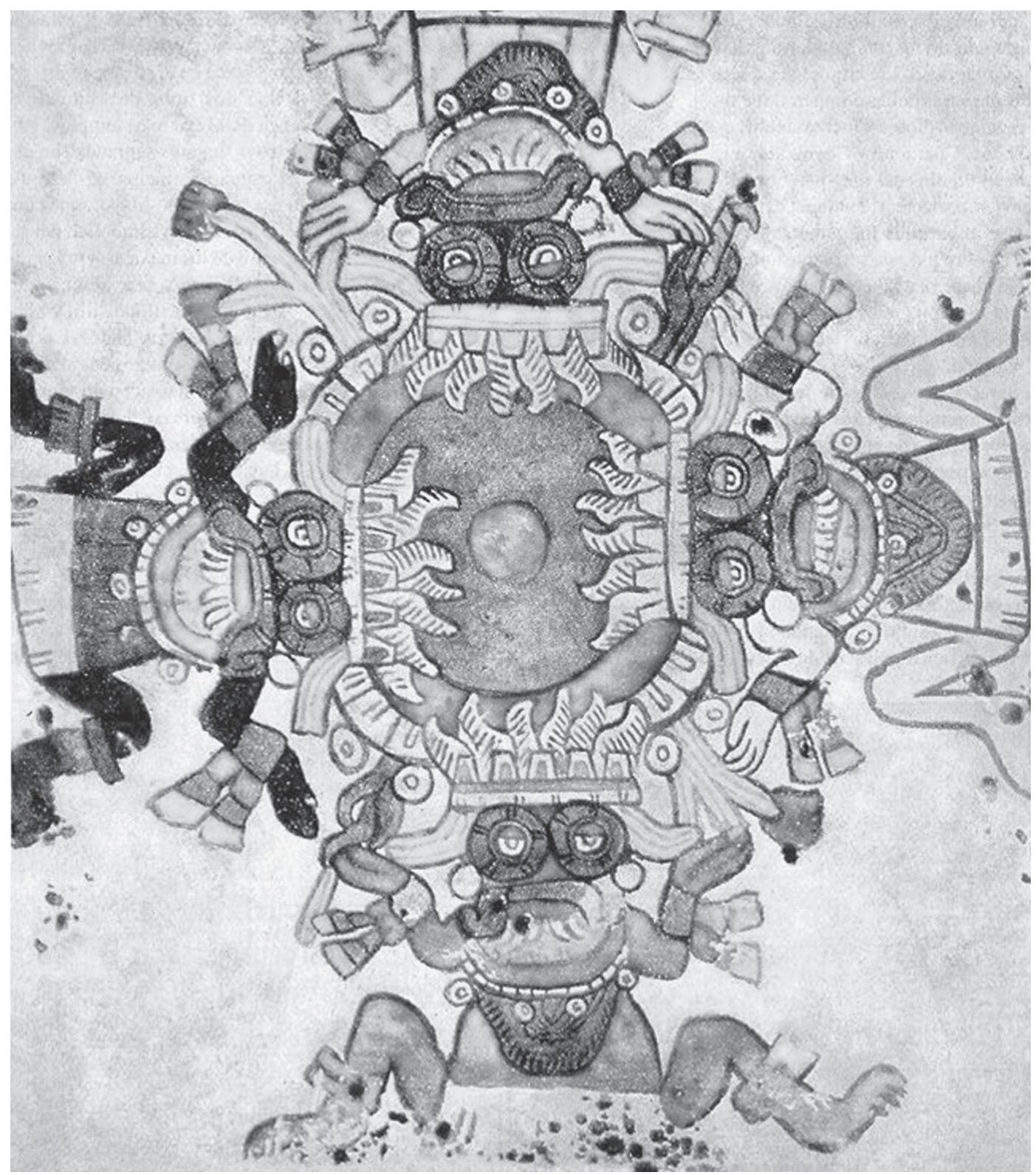

Fig. 9 - Decoração da tampa da petlacalli de Tizapán, representando os quatro tlaloques nas quatro direções e um chalchihuitl ao centro (extraído de Broda 1996).

Observamos, portanto, um privilegiamento do chalchihuitl nas delimitações do centro do universo, como nos conjuntos harmônicos das páginas 27 e 28 do Borgia, no Lagarto no centro da página 23 do Laud - fenômeno reiterado pelos exemplos arqueológicos mencionados da caixa de Tizapán e das oferendas 16 e 41 do Templo Mayor. Essa posição central parece estar vinculada ao centro da grande montanha, morada de Tlaloc - Tlalocan - fonte das águas e da vida terrena, que segundo López Austin é também Tamoanchan, lugar de equilíbrio e síntese das quatro direções, ponto de contato entre os deuses e os seres terrenos, 


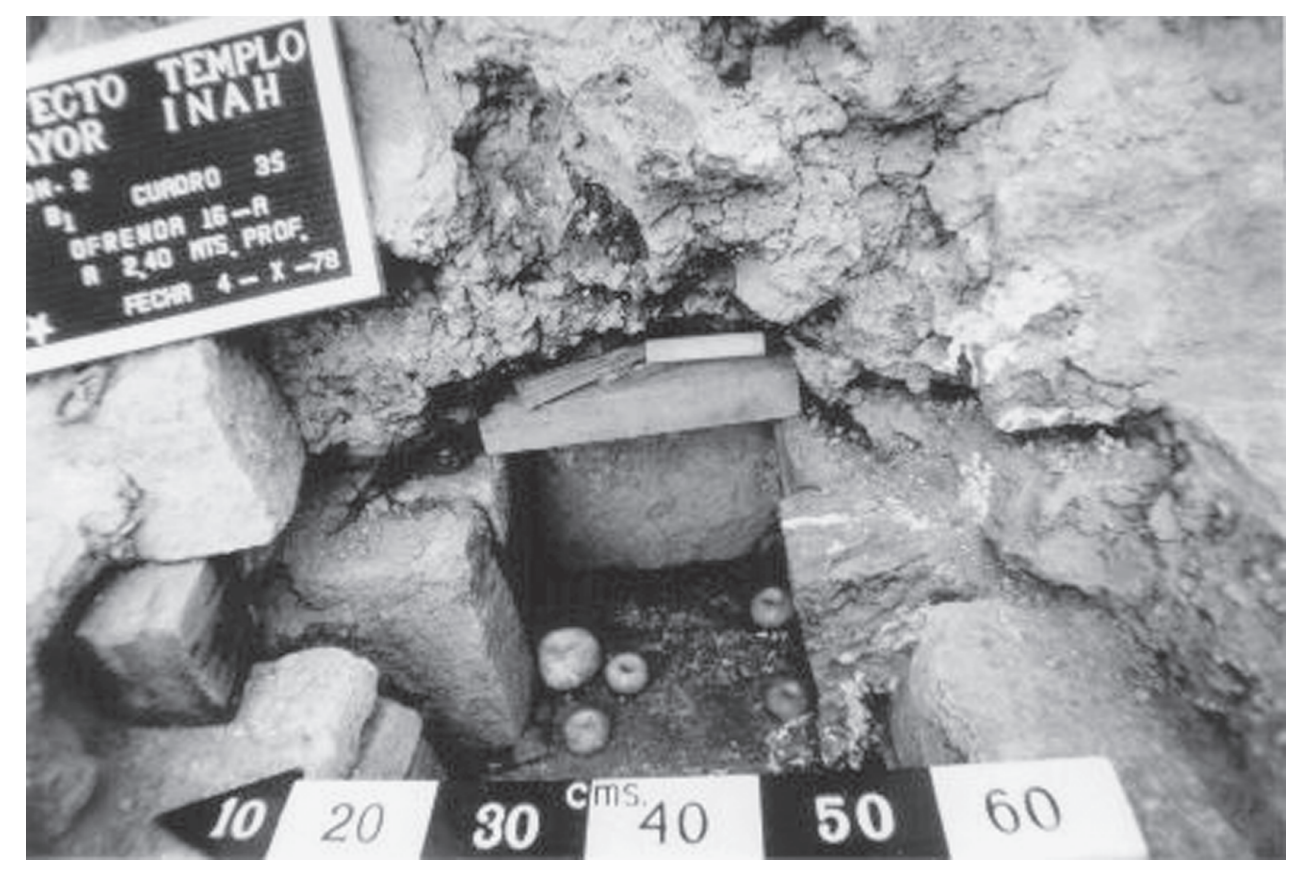

Fig.10 - Oferenda 16-A exibindo chalchihuites que assinalam os rumos cósmicos (Foto de Salvador G. Arroyo, Arquivos do Museu do Templo Mayor).

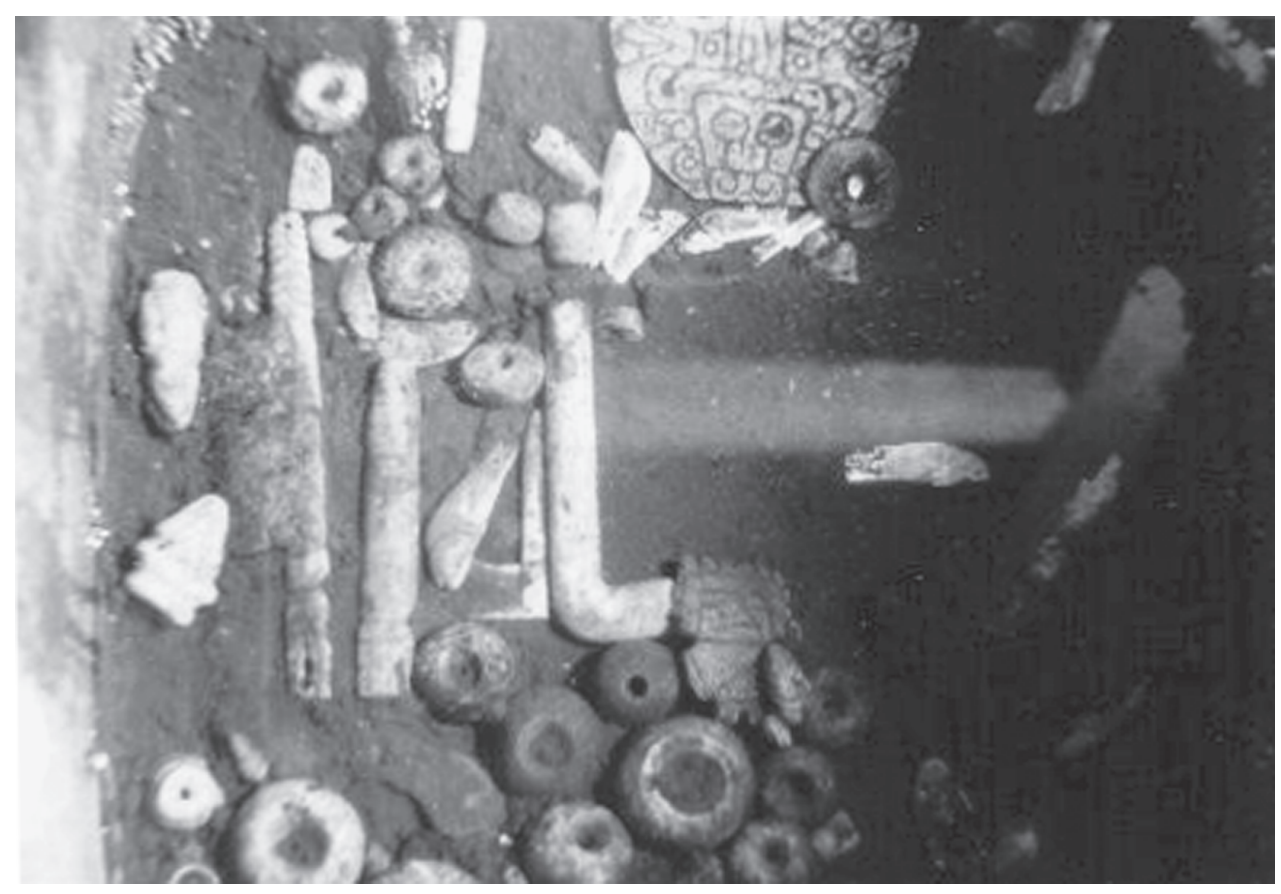

Fig 11 - Oferenda 41, representando uma petlacalli cheia de tesouros aquáticos (Foto de Salvador G. Arroyo, Arquivos do Museu do Templo Mayor). 
FRANÇA, L.M. O simbolismo do jade nos teoamoxtli do Grupo Borgia. Rev. do Museu de Arqueologia e Etnologia, São Paulo, 14: 225-239, 2004.

sítio de contínua transformação, em outras palavras, de fertilidade. O chalchihuitl é, assim, o símbolo de vida por excelência (López Austin 1994).

Não é, pois, difícil compreender porque o jade constituiu, no México Antigo, a expressão máxima de preciosidade. Na verdade, em um nível de leitura mais profundo, os teoamoxtli evidenciam de forma muito nítida - através do uso sistemático do chalchihuitl em seu sistema de escrita - a importância decisiva da água para as populações mesoamericanas, que construíram Estados poderosos em uma dependência contínua da natureza enquanto fonte absoluta de vida e criação.

FRANÇA, L.M. The jade symbolism in the teoamoxtli of the Borgia group. Rev. do Museu de Arqueologia e Etnologia, São Paulo, 14: 225-239, 2004.

ABSTRACT: The jade - like other similar greenstones - was very high valued among Mesoamerican peoples. For its green color and resemblance with water and vegetation it was related to a complex water symbolism, which converted it in the maximum expression of preciousness. It can be found in the teomoxtli - the ritual pictorial native books - and under the form of the glyph chalchihuitl (jade), in several contexts, rules that guide the usage of the term, and that show how the jade carried a strong water and fertility meaning content.

UNITERMS: Jade-Mesoamerica-Aquatic Symbolism-Pre-Hispanic Codexes.

\section{Referências bibliográficas}

BRODA, J.

1982 E1 culto mexica de los cerros y del agua. Multidisciplina, México, UNAM-Acatlán, 7:45-56.

1996 Paisajes rituales del Altiplano central. Arqueologia Mexicana: Los dioses de Mesoamérica. Vol IV, 20, Julio-Agosto: 40-49.

BROTHERSTON, G

1997 La América indigena en su literatura: los libros del cuarto mundo. México: FCE.

CODICE BORGIA. LOS TEMPLOS DEL CIELO Y DE LA OSCURIDAD. ORACULOS Y LITURGIA

1993 Introdução e explicação de Ferdinand Anders, Maarten Jansen e Luis Reyes García. México: FCE.

CODICE COSPI. CALENDÁRIO DE PROGNÓSTICOS E OFRENDAS

1994 Introdução e explicação de Ferdinand Anders, Maarten Jansen e Peter Van der Loo. México: FCE.

CODICE FEJËRVÁRY-MAYER. EL LIBRO DE TEZCATLIPOCA SEÑOR DEL TIEMPO

1994 Introdução e explicação de Ferdinand Anders, Maarten Jansen e Gabina Aurora Perez Jimenez. México: FCE.
CODICE LAUD. LA PINTURA DE LA MUERTE Y DE LOS DESTINOS

1994 Introdução e explicação de Ferdinand Anders, Maarten Jansen, com contribuição de Alejandra Cruz Ortiz. México: FCE.

ELIADE, M.

1993 Tratado de História das Religiões. São Paulo: Martins Fontes.

FRANÇA. L.

1999 Transformações da Noção de Valor na Mesoamérica: os 'Objetos Preciosos' como Intermediários nas Trocas Indigenas e o seu Encontro com a Moeda Metálica. Dissertação de Mestrado. São Paulo, FFLCH/USP.

HEYDEN, D.

1998a Las cuevas de Teotihuacan. Arqueologia Mexicana: Ritos de México Préhispánico. Vol. VI, 34, novembro-dezembro: 18-27.

1998b México. Orígenes de un simbolo. México: INAH.

LÓPEZ-AUSTIN, A.

1994 Tamoanchán y Tlalocán. México: FCE. LÓPEZ LUJÁN, L.

1994 The Offerings of the Templo Mayor of Tenochtitlan. Niwot, University Press of Colorado. 
FRANÇA, L.M. O simbolismo do jade nos teoamoxtli do Grupo Borgia. Rev. do Museu de Arqueologia e Etnologia, São Paulo, 14:225-239, 2004.

\section{PAZTORY, E.}

1974 The Iconographiy of the Teotihuacan Tlaloc Studies in Pre-Columbian Art \& Archaeology, 15. Washington, D.C. Dumbarton Oaks.

\section{SAHAGÚN, BERNARDINO, FREI}

1975 História General de las Cosas de la Nueva España. México: Editoria Porrua.

\section{SPRAJC, I.}

2001 La Astronomia. L. Manzanilla; e L. López Luján (Eds.) Historia Antigua de Mexico. México, UNAM/INAH.

\section{THOUVENOT, $\mathrm{M}$.}

1982 Les Jades chez les Astèques. Paris: Institut D'Ethnologie.

Recebido para publicação em 18 de novembro de 2004. 